\title{
Microaspersores entupidos devido a problemas de ferro na água
}

\author{
Microsprinkler clogged due to iron problems in the water
}

\author{
Túlio Assunção Pires RibeiroI José Euclides Stipp Paterniani"
}

\begin{abstract}
Um dos aspectos relevantes a ser considerado no manejo da irrigação é a uniformidade de distribuição de água pelo sistema. Este trabalho foi desenvolvido com o objetivo de avaliar a eficiência da cloração com a utilização de hipoclorito de sódio na desobstrução de microaspersores devido à utilização de águas com elevado teor de ferro. Um sistema com dez meses de uso apresentava setores com vazões de 5\% a 57\% menores que a vazão de projeto. Foi feito o tratamento químico da água de irrigação, utilizando-se hipoclorito de sódio com $12 \%$ de cloro livre na dosagem de $100 \mathrm{mg} \mathrm{L}^{-1}$ e ácido sulfúrico, na concentração de $98 \%$, para manter o pH da água de irrigação em torno de 4,5. O resultado indicou que houve aumento significativo nas vazões médias dos microaspersores em todos os setores avaliados e diminuição na variação da vazão dos mesmos com relação à estimada no projeto.
\end{abstract}

Palavras-chave: obstrução de emissores, qualidade de água, irrigação localizada.

\section{ABSTRACT}

An important aspect to be considered in irrigation managment is the uniformity distribution of water through the irrigation system. This research had the objective to evaluate the efficiency of chlorination in the use of sodium hypochlorite in clearing of microsprinkler due to the presence of high iron concentration in water. The equipment with less than a year of use presenting sectors with 5\% and 57\% lower flow than the original project flow. The chemical treatment of water irrigation utilized sodium hypochlorite with $12 \%$ free chlorine on $100 \mathrm{mg}$ $L^{-1}$ concentration, and sulphuric acid $98 \%$ to maintain the $\mathrm{pH}$ of water irrigation about 4.5. The result demonstrated a significant increase in the average flow of the microsprinkler's variation in all evaluted setors, and decrease in their flow variation related to the estimated in the project.

Key words: emitters' clogging, water quality, trickle irrigation.

O bom desempenho dos sistemas de irrigação localizada deve ser maximizado a fim de assegurar uma relação custo/benefício favorável. Portanto, se os emissores entopem em um curto espaço de tempo, os procedimentos de recuperação adicionarão custos para a manutenção do sistema, levando à queda de produtividade e qualidade dos produtos.

Em trabalho sobre recuperação de gotejadores entupidos devido a problemas de ferro na água, VIEIRA et al (2004) constataram que a aplicação de ácido fosfórico na água para controle do $\mathrm{pH}$ associado com a utilização de hipoclorito de sódio com $12 \%$ de cloro livre resultou em melhoria na uniformidade de aplicação de água pelo sistema de irrigação, por meiodo aumento nos valores do coeficiente de uniformidade de distribuição (CUD) e do coeficiente de uniformidade de Christiansen (CUC).

O objetivo do presente trabalho foi avaliar o grau de desobstrução dos microaspersores por meio do cálculo da uniformidade de distribuição de água do sistema de irrigação por microaspersão e da variação da vazão dos mesmos em relação à vazão de projeto.

O experimento foi realizado na Fazenda Santa Maria, Pirassununga-SP. Aárea irrigada é de 153 hectares. A irrigação é feita por um sistema de irrigação por

'Departamento de Água e Solo, Faculdade de Engenharia Agrícola, Universidade Estadual de Campinas (UNICAMP), CP 6011, 13083-875, Campinas, SP, Brasil. E-mail tulior@agr.unicamp.br. Autor para correspondência.

"UNICAMP, Campinas, SP, Brasil. 
microaspersão marca Naandan, microaspersor modelo Dan Jet 7200, com vazão nominal de $19 \mathrm{~L} \mathrm{~h}^{-1}$, autocompensante, com 10 meses de funcionamento. Realizou-se análise preliminar dos fatores relacionados com a qualidade da água de irrigação para sistema de irrigação localizada que podem causar obstrução nos emissores, cujos resultados estão apresentados na tabela 1.

Os resultados da análise preliminar das amostras de água da captação e dos três setores avaliados (Tabela 1) indicam alto risco de entupimento com relação ao ferro e moderado devido ao pH, com relação à água de captação do sistema de irrigação. Para os setores 5B (setor na cota mais baixa), 4A (setor na cota mais alta e mais distante do cabeçal de filtragem), 3C (setor mais próximo ao cabeçal de filtragem), verificase que todos os três setores apresentaram alto risco de entupimento devido ao ferro e moderado devido ao $\mathrm{pH}$ e manganês. Os setores 4A e 5B também apresentaram problemas moderados com relação a sólidos suspensos e à turbidez. Estes problemas são conseqüência do acúmulo de sujeiras presentes na água da captação que foram se acumulando nas laterais destes setores, devido à sedimentação, tendo em vista que os valores destes dois parâmetros são maiores que no ponto de captação (Tabela 1).
O fato de as concentrações de ferro serem maiores nos três setores analisados em comparação com a captação (Tabela 1) é devido à precipitação em conseqüência da oxidação deste elemento. Isso ocorre porque o ferro reduzido $\left(\mathrm{Fe}^{2+}\right)$ e, portanto, solúvel, ao atravessar o sistema de filtragem, pode se oxidar, tornando-se insolúvel $\left(\mathrm{Fe}^{3+}\right)$ e acaba se precipitando e causando obstrução dos emissores VIEIRA et al. (2004).

Antes do tratamento químico fez-se um teste preliminar nos três setores, em que se determinou a vazão dos microaspersores, mediu-se a pressão no início e final das linhas laterais e a uniformidade de distribuição de água de cada setor. Depois foram comparados os dados de vazão coletados em campo com a vazão do microaspersor de acordo com o catálogo do fabricante, ou seja, vazão de projeto do sistema de irrigação. O tratamento químico da água foi feito com hipoclorito de sódio ( $\mathrm{NaClO}$ ), que contém $12 \%$ de cloro livre, na concentração de $100 \mathrm{mg} \mathrm{L}^{-1}$, juntamente com ácido sulfúrico $\left(\mathrm{H}_{2} \mathrm{SO}_{4}\right)$ na concentração de $98 \%$, utilizado para abaixar o pH da solução. Para determinação da quantidade de ácido a ser adicionada à água de irrigação, fez-se uma titulação até o pH da água atingir em torno de 4,5.

Os produtos químicos foram injetados na tubulação principal por meio de um sistema de controle

Tabela 1 - Resultados das análises dos parâmetros físicos, químicos e biológicos da qualidade da água da captação do sistema de irrigação e de três setores onde foram feitos os testes de vazão dos microaspersores, Pirassununga, SP.

\begin{tabular}{|c|c|c|c|c|c|c|c|c|c|}
\hline \multirow[b]{2}{*}{ Parâmetro } & \multirow[b]{2}{*}{ Unidade } & \multicolumn{2}{|c|}{------Captação------ } & \multicolumn{2}{|c|}{------Setor 3C------ } & \multicolumn{2}{|c|}{------Setor 4A------ } & \multicolumn{2}{|c|}{------Setor 5B------ } \\
\hline & & Valor & $\begin{array}{l}\text { Risco de } \\
\text { entupir }^{(2)}\end{array}$ & Valor & $\begin{array}{l}\text { Risco de } \\
\text { entupir }^{(2)}\end{array}$ & Valor & $\begin{array}{l}\text { Risco de } \\
\text { entupir }^{(2)}\end{array}$ & Valor & $\begin{array}{l}\text { Risco de } \\
\text { entupir }^{(2)}\end{array}$ \\
\hline $\begin{array}{l}\text { Sólidos } \\
\text { suspensos }\end{array}$ & $\mathrm{mg} \mathrm{L}^{-1}$ & 48 & baixo & 15 & baixo & 65 & moderado & 65 & moderado \\
\hline Turbidez & NTU & 42 & baixo & 16 & baixo & 44,5 & moderado & 49,5 & moderado \\
\hline $\mathrm{pH}$ & & 7,5 & moderado & 7,6 & moderado & 7,6 & moderado & 7,6 & moderado \\
\hline Sais dissolvidos & $\mathrm{mg} \mathrm{L}^{-1}$ & 27,5 & $\begin{array}{l}\text { muito } \\
\text { baixo }\end{array}$ & 21,7 & $\begin{array}{l}\text { muito } \\
\text { baixo }\end{array}$ & 20,5 & $\begin{array}{l}\text { muito } \\
\text { baixo }\end{array}$ & 20,5 & $\begin{array}{l}\text { muito } \\
\text { baixo }\end{array}$ \\
\hline $\begin{array}{l}\text { Condutividade } \\
\text { elétrica }\end{array}$ & $\mu \mathrm{S} \mathrm{cm}{ }^{-1}$ & 43 & $\begin{array}{l}\text { muito } \\
\text { baixo }\end{array}$ & 34 & $\begin{array}{l}\text { muito } \\
\text { baixo }\end{array}$ & 32 & $\begin{array}{l}\text { muito } \\
\text { baixo }\end{array}$ & 32 & $\begin{array}{l}\text { muito } \\
\text { baixo }\end{array}$ \\
\hline Manganês & $m g L^{-1}$ & $\operatorname{ALD}^{(1)}$ & $\begin{array}{l}\text { muito } \\
\text { baixo }\end{array}$ & $\mathrm{ALD}^{(1)}$ & baixo & 0,2 & moderado & 0,5 & moderado \\
\hline Ferro & $\mathrm{mg} \mathrm{L}^{-1}$ & 2,3 & muito alto & 2,8 & $\begin{array}{l}\text { muito } \\
\text { alto }\end{array}$ & 3,1 & muito alto & 2,6 & muito alto \\
\hline $\begin{array}{l}\text { Sulfetos de } \\
\text { hidrogênio }\end{array}$ & $m g L^{-1}$ & $\operatorname{ALD}^{(1)}$ & baixo & $\mathrm{ALD}^{(1)}$ & & $\mathrm{ALD}^{(1)}$ & & $\operatorname{ALD}^{(1)}$ & \\
\hline Dureza & $\mathrm{mg} \mathrm{L}^{-1}$ & 2,4 & $\begin{array}{l}\text { muito } \\
\text { baixo }\end{array}$ & 2,9 & $\begin{array}{l}\text { muito } \\
\text { baixo }\end{array}$ & 3,1 & $\begin{array}{l}\text { muito } \\
\text { baixo }\end{array}$ & 2,3 & $\begin{array}{l}\text { muito } \\
\text { baixo }\end{array}$ \\
\hline $\begin{array}{l}\text { População de } \\
\text { bactérias }\end{array}$ & $\mathrm{n}^{0} \mathrm{~cm}^{-3}$ & 30 & $\begin{array}{l}\text { muito } \\
\text { baixo }\end{array}$ & 30 & $\begin{array}{l}\text { muito } \\
\text { baixo }\end{array}$ & 300 & $\begin{array}{l}\text { muito } \\
\text { baixo }\end{array}$ & 30 & $\begin{array}{l}\text { muito } \\
\text { baixo }\end{array}$ \\
\hline
\end{tabular}

1) Abaixo do Limite de Detecção.

2) O grau de risco de entupimentos é baseado em literatura internacional de acordo com NAKAYAMA e BUCKS (1986). 
de injeção, constituído de uma bomba centrífuga para a injeção da solução de hipoclorito e outra bomba dosadora para injeção de ácido sulfúrico. O modo de aplicação foi idêntico em todos os setores avaliados, fazendo-se três aplicações em cada um. A primeira, com duração de 10 minutos, enquanto a segunda e a terceira foram feitas com duração de uma hora cada uma. A aplicação de 10 minutos foi necessária para permitir que as reações com compostos orgânicos e de ferro ocorressem, além do que correspondia ao tempo de deslocamento da solução até o final das linhas de irrigação. Acredita-se que esse tempo seja suficiente para ter-se boa eficiência na cloração porque a maior parte dos vírus e das bactérias são inativados de 10 a 30 minutos de contato com o cloro (LOPEZ et al. 1997). Este procedimento ajudou a evitar que ocorresse o problema de desprendimento de partículas maiores e estas fossem parar dentro do microaspersor, agravando o problema de entupimento. Terminada a aplicação, o sistema era imediatamente desligado e deixado em repouso por aproximadamente 12 horas, quando era feita a abertura dos finais de linha e era novamente ligado o sistema para realizar a lavagem das tubulações, que eram fechadas assim que se constatava a saída de água limpa por pelo menos 2 minutos, garantindo, assim, que todo o material desprendido fosse eliminado do sistema. Terminado o processo de limpeza, imediatamente foi feita a avaliação de uniformidade.

A metodologia de cálculo consiste na utilização de um método estatístico para a estimativa da uniformidade de distribuição de água no campo de subparcelas ou setores, baseados no coeficiente de uniformidade estatística (Us), equação 1, e o coeficiente de variação $(\mathrm{CV})$, equação 2 .

Us $=100(1-C V)$

Onde:

Us - uniformidade estatística de emissão (\%);

CV - coeficiente estatístico de variação de vazão dos emissores.

$$
C V=\frac{s}{\bar{q}}
$$

Onde:

s - desvio padrão $\left(\mathrm{L} \mathrm{h}^{-1}\right)$;

$\overline{\mathrm{q}}$ - vazão média total $\left(\mathrm{L} \mathrm{h}^{-1}\right)$.

Dentro de cada setor foram avaliadas cinco

linhas de microaspersores, que estavam localizadas em cotas topográficas diferentes. Os pontos estavam localizados no início, 1/3, 1/2, 2/3 do comprimento e no final da linha, totalizando 18 pontos por setor.

Nos setores $5 B$ e $3 \mathrm{C}$, antes do tratamento químico, embora mostrem coeficientes de uniformidade excelente e razoável, respectivamente, a vazão média dos setores está bem abaixo da vazão de projeto (19L $\mathrm{h}^{-1}$ ), ou seja, apresentam variações da vazão de projeto bem inferior à vazão desejada (Tabela 2). Isso indica que boa parte dos setores estava com problemas de entupimento.

A uniformidade inicial (antes do tratamento) nos setores 4A e 5B estava excelente e permaneceu com valores satisfatórios depois do tratamento, enquanto que no setor 3C ocorreu ligeira diminuição da uniformidade, passando de razoável (76,58 \%) antes do tratamento para ruim $(69,49 \%)$ (Tabela 2$)$. Por outro lado, ocorreu diminuição da variação da vazão em relação à vazão de projeto, devido ao aumento da vazão média dos microaspersores em todos os setores. Este mesmo fato ocorreu em trabalho realizado por CORDEIRO (2002) e VIEIRA et al (2004), em estudo sobre desentupimento de gotejadores devido a problemas de ferro na água de irrigação. Os autores utilizaram para o tratamento de limpeza o produto Reciclean (produto comercial próprio para limpeza de sistemas de irrigação fabricado pela empresa Kemira), sendo que o sistema de irrigação permaneceu com o índice de uniformidade tanto antes como depois do tratamento químico na mesma faixa, ou seja, razoável. De acordo com os autores, isso ocorre porque, em certos casos, pode ocorrer desprendimento de partículas aderidas à parede interna da tubulação, que se deslocarão para o interior dos gotejadores, piorando ainda mais o problema de entupimento.

Do ponto de vista prático, a vazão média dos microaspersores de cada setor pode ser considerada como um bom parâmetro para avaliar o processo de entupimento, sendo utilizada em muitos trabalhos pertinentes (RAVINA el al, 1992). Portanto, a observação dos dados de aumento das vazões médias dos microaspersores comprova a eficiência do tratamento, visto que o mesmo causou também aumento das pressões médias nos finais de linha dos três setores avaliados (Tabela 2).

A mistura de hipoclorito de sódio (12\%) com ácido sulfúrico para $\mathrm{pH}$ 4,5 é uma excelente opção para a desobstrução de sistema de irrigação por microaspersão com problemas de vazão devido à presença de altas concentrações de ferro na água. 


\section{REFERÊNCIAS}

BRALTS, F.V.; KESNER, D.C. Drip irrigation field uniformity estimation. Transactions of the American Society Agricultural Engineer, v.26, n.5, p.1369-1374. 1983

CORDEIRO, E.A. Influência do tratamento de água ferruginosa no desempenho de sistema de irrigação por gotejamento. 2002. 92f. Dissertação (Mestrado em Irrigação) - Faculdade de Engenharia Agrícola, Universidade Federal de Viçosa.
LOPEZ, R.J. et al. Riego localizado. 2.ed. Madri: MundiPrensa, 1997. 405p.

NAKAYAMA, F.S; BUCKS, D.A. Trickle irrigation for crop production: design, operation and management. Amsterdam: Elsevier, 1986. 383p.

RAVINA, I. et al. Control of emitter clogging in drip irrigation with reclaimed wastewater. Irrigation Science, v.13, p.129139, 1992

VIEIRA G.H.S. et al. Recuperação de gotejadores obstruídos devido à utilização de águas ferruginosas. Revista Brasileira de Engenharia Agrícola e Ambiental, v.8, n.1, p.1-6, 2004.

Tabela 2 - Resultados e comparação da avaliação do tratamento químico para a limpeza dos três setores do sistema de irrigação, ant迎 e depois do tratamento químico de limpeza, em Pirassununga, SP.

\begin{tabular}{|c|c|c|c|c|c|c|c|c|c|c|}
\hline \multirow{2}{*}{ Setor } & \multicolumn{2}{|c|}{ Coef. Unif $(\%)^{1}$} & \multicolumn{2}{|c|}{ Classificação } & \multicolumn{2}{|c|}{ Vazão média $\left(\mathrm{L} \mathrm{h}^{-1}\right)$} & \multicolumn{2}{|c|}{$\begin{array}{l}\text { \% V ariação da vazão de } \\
\text { projeto }\end{array}$} & \multicolumn{2}{|c|}{ Pressão média ${ }^{5}(\mathrm{kPa})$} \\
\hline & antes $^{3}$ & depois ${ }^{4}$ & antes $^{3}$ & depois $^{4}$ & antes $^{3}$ & depois $^{4}$ & antes $^{3}$ & depois $^{4}$ & antes $^{3}$ & depois $^{4}$ \\
\hline $4 \mathrm{~A}$ & 94,2 & 93,5 & Excelente & Excelente & 18,0 & 18,5 & $-5,0$ & $-2,4$ & 158,9 & 196,1 \\
\hline $5 B$ & 94,2 & 93,5 & Excelente & Excelente & 9,7 & 19,2 & $-49,0$ & 1,0 & 249,1 & 266,7 \\
\hline $3 C$ & 76,6 & 69,5 & Razoável & Ruim & 8,2 & 15,9 & $-56,8$ & $-16,5$ & 149,1 & 168,7 \\
\hline
\end{tabular}

(1) O coeficiente de uniformidade foi determinado de acordo com metodologia desenvolvida por BRALTS \& KESNER (1983).

(2) De acordo com a classificação proposta por BRALTS \& KESNER (1983).

(3) Valores antes do tratamento químic o de limpeza.

(4) Valores depois do tratamento químico de limpeza.

(5) Pressão média dos finais de linha. 